\title{
Airways oxidative stress, lung function and cognitive impairment in aging
}

\author{
C. Gramiccioni1,3, G.E. Carpagnano1, A. Spanevello1,2, \\ V. Turchiarelli1, M.G. Cagnazzo ${ }^{1}$, M.P. Foschino Barbaro1
}

\begin{abstract}
Airways oxidative stress, lung function and cognitive impairment in aging. C. Gramiccioni, G.E. Carpagnano, A. Spanevello, V. Turchiarelli, M.G. Cagnazzo, M.P. Foschino Barbaro.

Background. An altered balance of oxidants/anti-oxidants is one of the pathological mechanisms of many agedependent disorders. We aimed to investigate the age-related airways oxidative stress, using non invasive, safe and repeatable techniques; to evaluate the correspondence between systemic and local oxidative stress in healthy subjects of different age ranges; to analyse the correlation between systemic and local oxidative stress with lung function and with cognitive impairment.

Methods. Thirty consecutive healthy high school graduated subjects $(8 \mathrm{M}, 22 \mathrm{~F})$, divided in three ranges of age ( $<35$; between 35 and 60 ; $>60$ years) were enrolled. All subjects underwent oxygen free radicals and exhaled nitric oxide measurement (by the diacron reactive oxygen metabolites test and by a rapid-response chemilumines-
\end{abstract}

cence nitric oxide analyzer), lung function tests, and cognitive impairment scales (Mini Mental State Examination and Geriatric Depression Scale).

Results. A significant increase of oxygen free radicals, exhaled nitric oxide, and Geriatric Depression Scale score and a significant decrease of forced expiratory volume in 1 second and forced expiratory vital capacity from younger to older subjects were identified. Moreover, the significant positive correlation between oxygen free radicals and exhaled nitric oxide, and between oxygen free radicals and exhaled nitric oxide with Geriatric Depression Scale score were found. The significant negative correlation between forced expiratory volume in 1 second and oxygen free radicals or exhaled nitric oxide was also demonstrated.

Conclusions. Our data supports the role of progressive local oxidative stress in damaging the lung function and in inducing depression symptoms.

Monaldi Arch Chest Dis 2010; 73: 1, 5-11.

Keywords: Elderly, Exhaled breath condensate, Oxidative stress, Cognitive impairment, Exhaled nitric oxide.

1 Institute of Respiratory Disease, Department of Medical and Occupational Sciences, University of Foggia,

2 Fondazione Salvatore Maugeri, Care and Research Institute, Cassano delle Murge, Bari,

3 Institute of Neurobiology and Molecular Medicine, Italian National Research Council, Rome, Italy.

Correspondence: Dr Giovanna Elisiana Carpagnano, Institute of Respiratory Diseases, University of Foggia, Ospedale D’Avanzo, Via degli Aviatori 1, 71100 Foggia, Italy; e-mail: ge.carpagnano@unifg.it

\section{Introduction}

Oxidative stress has been a major topic for many years [1]. The role of free radicals in aging in fact, has been often studied. It is assumed that during aging, damaging effects of the oxygen free radicals may be accumulated in all components of the body. In fact, Reactive Oxygen Species (ROS) are normally generated by tightly regulated enzymes, such as NAD (P) H oxydase isoforms [2]. An overproduction of ROS is related to damage of cell structures such as lipids, proteins and DNA [2]. However, ROS are not only the cause of structural damage, but they are also physiologically important mediators in biological signalling processes, such as apoptosis [3].

During aging, the progressive deficit of antioxidant physiologic systems corresponds to this increase of free radicals, leading to an altered balance of oxidants/anti-oxidants that is one of the pathological mechanisms of many age-dependent disorders [4-6].

The role of ROS in lung diseases has been often studied. Lungs are continuously exposed to ox- idants generated either endogenously or exogenously from air pollutants or cigarette smoke [7]. Cigarette smoke can damage lungs by various mechanisms such as depletion of glutathione and other anti-oxidants or initiation of redox cycling mechanisms [7]. The oxidation of proteins has an important role in the pathogenesis of chronic inflammatory lung diseases, such as Chronic Obstructive Pulmonary Disease (COPD), but high plasmatic levels of ROS have also been demonstrated in cystic fibrosis, asbestosis and idiopathic pulmonary fibrosis [8-10].

Lung inflammation has been found in healthy subjects during aging, as demonstrated by the increase of neutrophils in induced sputum of these subjects [11]. Oxidative stress is strictly related to lung inflammation because the recruited inflammatory cells are able to release free radicals, responsible for tissue damage $[12,13]$.

Usually, ROS are measured by assessing the plasmatic derivatives of reactive oxygen metabolites (D-ROMS). However, the possibility that the oxidative stress is also present in airways has been recently suggested $[14,15]$. In the last decade, the interest 
in studying airways using non invasive methods, such as induced sputum, exhaled NO and exhaled breath condensate has increased $[11,16]$. These completely non-invasive, safe and repeatable techniques, are ideal to study lung inflammation parameters such as exhaled nitric oxide (NO) in the elderly.

Moreover, aging is known to be accompanied by the decrease of respiratory function, characterised by a progressive decrease of the dynamic indices (forced expiratory volume in 1 second - $\mathrm{FEV}_{1}$ - and forced expiratory vital capacity FVC), probably due, at least in part, to airways inflammation and oxidative stress [17]. To our knowledge, this interesting possible association has been poorly investigated.

Aging process is also characterised by the decline of cognitive functions. The role of oxygen radicals and ROS in neurodegeneration and cognitive decline has been demonstrated previously [1820]. The age-related increase in oxidative brain damage is well exemplified by products of lipid peroxidation, protein oxidation and oxidative modifications in nuclear and mithocondrial DNA [21].

In animal models, the age-related decline in memory function has been ameliorated by $\mathrm{N}$ acetyl-cysteine (NAC), which increases the availability of cellular anti-oxydants, such as cysteine and intracellular GSH [22, 23].

However, few studies on humans are available. Ultraoctagenarian population was analysed by Maugeri et al [4] in order to reveal a possible correlation between the free radical levels and the psycho-physical health status. The statistically significant negative correlation between D-ROMS and the cognitive performance was demonstrated in this study.

In order to better understand the age-related oxidative stress and to evaluate the correspondence between systemic and local oxidative stress, we measured plasmatic levels of ROMS and exhaled NO in healthy subjects of different ranges of age. Possible correlations between ROMS, exhaled NO and lung function were analysed.

Moreover, the enrolled subjects underwent cognitive tests in order to evaluate possible correlations between systemic and/or local oxidative stress and cognitive impairment.

\section{Material and methods}

\section{DESIGN OF THE STUDY}

The systemic and local oxidative stress in different age ranges of healthy subjects and its correlation with lung function and cognitive impairment were investigated.

\section{Subjects}

The study population consisted of 30 healthy high school graduate adults ( $8 \mathrm{M}, 22 \mathrm{~F})$, divided in three groups on the basis of the age: 1) 10 subjects aged under 35 years $(25.9 \pm 4.9 \mathrm{yr}),(\mathrm{A}), 2) 10 \mathrm{sub}-$ jects aged between 35 and 60 years $(52 \pm 5.9)(B)$, and 3) 10 subjects over 60 years $(67.3 \pm 4.6)$ (C).
All subjects were Caucasians, recruited from the Respiratory Disease Institute, University of Foggia. Informed written consent was obtained from all subjects and the study was approved by the Institutional Ethics Committee. All subjects were current non-smoker. Subjects with experienced respiratory symptoms or respiratory diseases and with clinical conditions associated with major elevation of inflammatory parameters (acute or chronic viral and bacterial infection, cancer, connective diseases, inflammatory bowel diseases, therapy with corticosteroids or immune-modulating agents, thromboembolic events or surgery in the preceding six months, endocrine diseases other that diabetes, liver or kidney diseases) were excluded.

On the first day, subjects underwent complete anamnesis, anthropometric and cognitive data and respiratory function tests collection. On the second day, subjects underwent exhaled NO measurement and blood tests. Subjects had not consumed anything and had not undergone any physical activity in the 60 minutes prior to the exhaled NO measurement.

\section{Pulmonary function testing}

Forced expiratory volume in one second $\left(\mathrm{FEV}_{1}\right)$ and forced vital capacity (FVC) and the $\mathrm{FEV}_{1} / \mathrm{FVC}$ ratio were measured using a spirometer (PK Morgan Ltd., Gillingham, UK). The best value of three manoeuvers was expressed as a percentage of the predicted normal value.

\section{Measurement of exhaled NO}

A rapid-response chemiluminescence NO analyser (NIOX) was used to quantify NO. Twopoint calibrations were performed daily using 5.2parts per million calibration gas. Exhaled NO $\left(\mathrm{F}_{\mathrm{E}} \mathrm{NO}\right)$ was measured using a previously described restricted breath technique, which employed expiratory resistance and positive mouth pressure to close the velum and exclude nasal NO, and a constant expiratory flow of $45 \mathrm{~mL} / \mathrm{s}$. Subjects inhaled to total lung capacity, and exhaled while targeting a constant pressure of $20 \mathrm{mmHg}$. Exhalations proceeded until a clear NO plateau of at least 3s duration was achieved. Repeated exhalations were performed until three plateaus agreed within $5 \%$.

\section{Plasma measurements}

\section{Plasma reactive oxygen metabolites measurement}

Systemic oxidative stress was measured by the diacron reactive oxygen metabolites (D-ROM) test (Diacron International, Italy). Values of D-ROMS were expressed as Carratelli Units, where 1 U.CARR corresponds to $0.8 \mathrm{mg} / \mathrm{L} \mathrm{H}_{2} \mathrm{O}_{2}$.

\section{Cognitive tests}

Cognitive impairment was evaluated by the Mini Mental State Examination (MMSE) and 
Geriatric Depression Scale (GDS). The use of GDS also in younger groups of study population was justified by previous demonstration of validity of GDS performance compared with other well-validated and reliable measures of depression, such as Beck Depression Inventory, also in younger subjects [24].

MMSE is a 30 items test, evaluating orientation in the time and in the space, memory and calculation ability. A score between 24 and 30 was considered normal, while a score $<24$ was considered pathological.

GDS, a 30 items test, is a basic screening measure for depression. The score interpretation was: 0-9 normal, 10-19: mild depression, 20-30: severe depression

The Italian authorised translation of these tests was self administered, according to the authors recommendations.

\section{Statistical analysis}

Data was expressed as means \pm SD. A MannWhitney test was used to compare groups, and correlations between variables were performed using Pearson's correlation test. The Significance was defined as a $p$ value of $<0.05$.

\section{Results}

\section{Subjects characteristics}

Anthropometric variables, functional, cognitive and oxidative stress data of studied subjects are shown in table 1 .

\section{Pulmonary function testing}

$\mathrm{FEV}_{1}$ showed significant decrease from group A to group C $(3.65 \pm 0.16 \mathrm{l} / \mathrm{m}$ vs $2.67 \pm 0.18 \mathrm{l} / \mathrm{m}$ vs $1.89 \pm 0.18 \mathrm{l} / \mathrm{m}$ ) (figure 1). The significant difference between group A and group B $(p<0.001)$, between group $\mathrm{B}$ and $\mathrm{C}(p<0.01)$ and between group $\mathrm{A}$ and $\mathrm{C}(p<0.0001)$ was observed. FVC decreased significantly from group A to group $C(4.4 \pm 1.0 \mathrm{vs}$ $2.9 \pm 0.6$ vs $2.3 \pm 0.6$ ) (A vs $B$ and $A$ vs $\mathrm{C}$ respectively $p<0.05$ and $p<0.01$ ).

\section{Exhaled NO}

Concentrations of exhaled NO were progressively higher from group A to group C $(5.3 \pm 1.0 \mathrm{vs}$ $8.8 \pm 1.0$ vs $11.0 \pm 1.2 \mathrm{ppb}$ ) (figure 2 ). The significant difference between groups (A vs B and A vs $\mathrm{C}$ respectively $p<0.05 ; p<0.005)$ was observed.

\section{ROMs}

Concentrations of oxygen free radicals (ROMS) were progressively increasing from group A to group C $(186.7 \pm 7.6$ U.CARR vs $273.6 \pm 8.4$ U.CARR vs $391.7 \pm 16.5$ U.CARR) (figure 3). The significant difference between group A and group B $(p<0.0001)$, between group B and C $(p<0.0001)$ and between group $\mathrm{A}$ and $\mathrm{C}(p<0.0001)$ was identified.

\section{Cognitive tests}

No significant difference was observed between the three groups analysed regarding MMSE scores $(30 \pm 0$ vs $30 \pm 0$ vs $30 \pm 0)$. The significant

Table 1. - Anthropometric, functional and systemic inflammation data in the population studied

\begin{tabular}{|c|c|c|c|}
\hline & $\begin{array}{c}<35 \\
(n=10)\end{array}$ & $\begin{array}{c}35-60 \\
(n=10)\end{array}$ & $\begin{array}{c}\text { over } 60 \\
(n=10)\end{array}$ \\
\hline Age (yr) & $26 \pm 4.9$ & $52 \pm 5.9$ & $67 \pm 4.6$ \\
\hline $\operatorname{FEV}_{1}(\mathbf{l} / \mathbf{m})$ & $3.6 \pm 0.16$ & $2.6 \pm 0.1 * *$ & $1.8 \pm 0.1 * * *$ \\
\hline $\mathrm{FEV}_{1} \%$ & $110.3 \pm 12.4$ & $100.1 \pm 9.7$ & $97.6 \pm 1.5$ \\
\hline $\operatorname{FVC}(1 / \mathbf{m})$ & $4.4 \pm 1$ & $2.9 \pm 0.6^{*}$ & $2.3 \pm 0.6 * *$ \\
\hline FVC\% & $109.3 \pm 9.8$ & $100.5 \pm 6.7$ & $98.8 \pm 5.6$ \\
\hline $\mathrm{FEV}_{1} / \mathrm{FVC} \%$ & $100.1 \pm 3.1$ & $100.3 \pm 2.6$ & $99.5 \pm 3.6$ \\
\hline ROMS (U.CARR) & $186.7 \pm 7.6$ & $273.6 \pm 8.4 * *$ & $391.7 \pm 16.5^{* *}$ \\
\hline NO (ppb) & $5.3 \pm 1.0$ & $8.8 \pm 1.0 *$ & $11.0 \pm 1.2 * *$ \\
\hline MMSE & $30 \pm 0$ & $30 \pm 0$ & $30 \pm 0$ \\
\hline GDS & $5.8 \pm 0.6$ & $8.4 \pm 0.6 * *$ & $11.5 \pm 0.8^{*}$ \\
\hline
\end{tabular}

Group of 35-60 and over 60 vs $<35=* p<0.05 ; * * p<0.01 ; * * * p<0.0001 . \mathrm{FEV}_{1}$ : forced expiratory volume in 1 second; FVC: forced expiratory vital capacity; GDS: Geriatric Depression Scale; MMSE: Mini Mental State Examination; NO: exhaled nitric oxide; ROMS, reactive oxygen metabolites. 


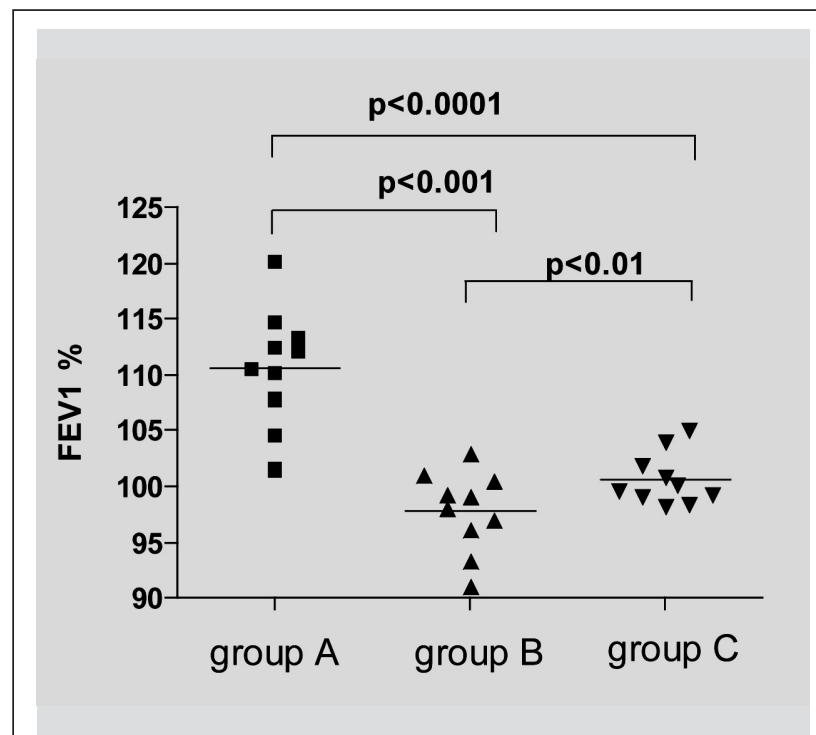

Fig. 1. $-\mathrm{FEV}_{1}$ values in three analysed groups. (Group A: $<35$ years; B: $>35$ and $<60$ years; $C:>60$ years).

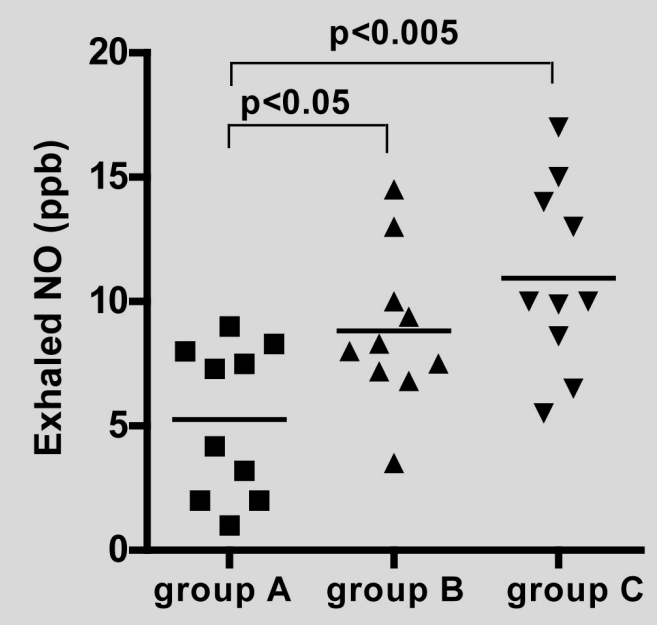

Fig. 2. - Exhaled NO levels in three analysed groups (Group A: $<35$ years; $\mathrm{B}:>35$ and $<60$ years; $\mathrm{C}:>60$ years).

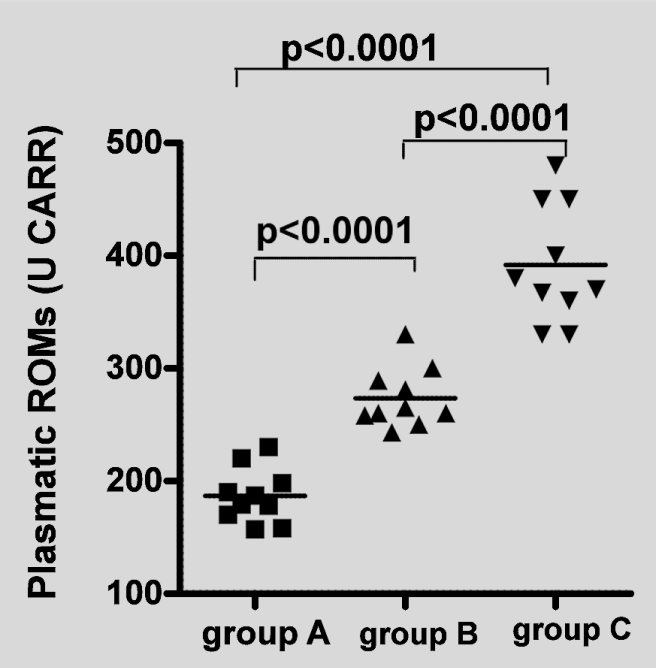

Fig. 3. - ROMS plasmatic levels in three analysed groups (Group A: $<35$ years; $\mathrm{B}:>35$ and $<60$ years; $\mathrm{C}:>60$ years). difference was observed regarding GDS scores (5.8 \pm 0.6 vs $8.4 \pm 0.6$ vs $11.5 \pm 0.8$ ) (A vs B: $p<0.01$; B vs $C: p<0.05$; A vs $C: p<0.001$ ) (figure 4 ).

\section{Correlations}

The relationships between systemic oxidative stress markers (plasmatic ROMS), airways oxidative stress markers (exhaled NO), lung function indices $\left(\mathrm{FEV}_{1}\right)$ and cognitive impairment (MMSE and GDS) were analyzed. The results are shown in table (table 2).

The significant positive correlation was observed between plasmatic ROMS and exhaled NO $(r=0.5 ; p<0.01)$; furthermore, the significant positive correlation was observed between plasmatic ROMS and GDS scores $(r=0.7, p<0.0001)$ and between exhaled NO and GDS score $(r=0.5, p<0.01)$ (figure 5).

The significant negative correlation was found between ROMS and $\mathrm{FEV}_{1}(r=-0.77, p<0.0001)$ (figure 6) and between exhaled $\mathrm{NO}$ and $\mathrm{FEV}_{1}$ $(r=-0.52, p<0.01)$ (figure 7).

\section{Discussion}

Little available data explain our interest in studying oxidative stress in elderly.

The strong correlation between lung inflammation and oxidative stress in lung diseases is well known. Inflammation is a protective response to tissue injury, but if this protection occurs in an uncontrolled manner, it results in a chronic inflammation [25]. During chronic inflammation, the recruitment of inflammatory cells, such as neutrophils and phagocytes, leads to ROS release and tissue damage $[12,26]$. In fact, activated neutrophils, macrophages and eosinophils generate $\mathrm{O}_{2}$. - which is converted into $\mathrm{H}_{2} \mathrm{O}_{2}$ by superoxide dismutase, and hydroxyl radicals, as secondary reaction. Lung cells in response to ROS release cytokines such as IL- 8 and TNF- $\alpha$ that induce neutrophil recruitment and activation of transcription factors, increasing the inflammatory process [27, 28]. ROS are highly reactive and they are able to deplete intracellular GSH (a physiological antioxidant) and oxidise membrane phospholipids, causing disruption of its function and cell death. ROS are also able to damage nuclear DNA and proteins in many inflammatory lung diseases [29].

Inhaled environmental oxidants may exacerbate the underlying inflammation in inflammatory lung diseases [25]. Ozone, the major component of air pollution particulates, is able to cause cellular damage by lipid peroxidation, neutrophil infiltration, increased airway responsiveness and reduced pulmonary function also in normal subjects [30]. Moreover, cigarette smoking contains many oxidants and free radicals and it causes airways neutrophils and macrophages infiltration, leading to oxidants release and inflammation [31].

By contrast, poor data is available regarding airways inflammation and oxidative stress in healthy subjects during aging, although several papers investigated systemic inflammation in elderly. 


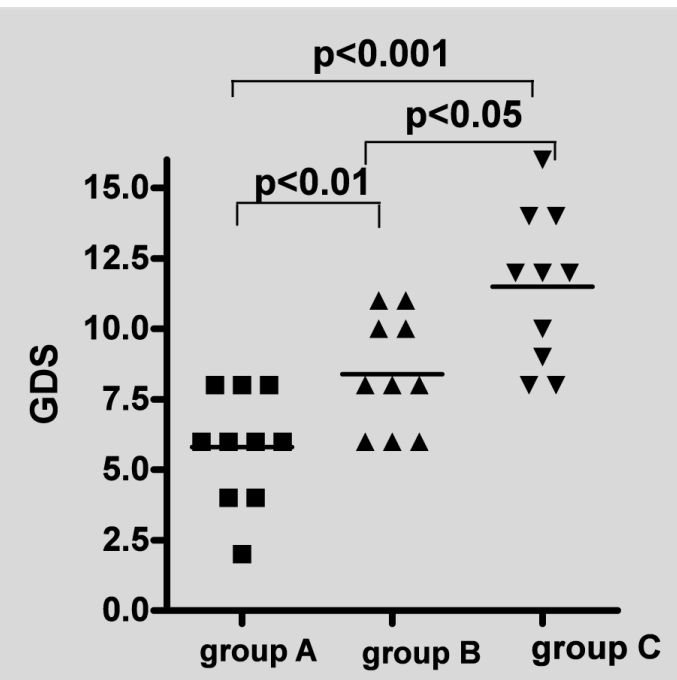

Fig. 4. - GDS scores in three analyzed groups (Group A: $<35$ years; B: $>35$ and $<60$ years; $\mathrm{C}:>60$ years).

In our previous research, the increase of airways inflammatory markers during aging have been demonstrated (unpublished data). The aim of the present study was to identify the correlation between the progressive increase of systemic and local oxidative stress during aging, lung function and cognitive impairment.

The progressive increase of exhaled NO during aging was demonstrated, according to the hypothesis that exhaled NO probably reflects underlying airways inflammation observed in elderly $[32,33]$. Furthermore, the positive correlation of exhaled NO with markers of systemic oxidative stress (ROMS) suggests a common mechanism underlying the systemic and local oxidative stress and highlights the utility of exhaled NO measurement in airways studies.

In agreement with previous publications, we demonstrated the progressive decrease of forced vital capacity (FVC) and forced expiratory volume in 1 second $\left(\mathrm{FEV}_{1}\right)$ during aging. The negative correlation with systemic and airways oxidative metabolites supports the role of oxidative stress, due to pollutants and cigarette smoke exposure during life, in damaging the lung function.

Several studies demonstrated progressive cognitive impairment during aging and they have re-

Table 2. - Correlations between systemic oxidative stress markers (plasmatic ROMS), airways oxidative stress markers (exhaled NO), lung function indices $\left(F V_{1}\right)$ and cognitive impairment (MMSE and GDS)

\begin{tabular}{lccc}
\hline & MMSE & GDS & FEV $_{\mathbf{1}}$ \\
\hline Exhaled NO & $\mathrm{ns}$ & $\mathrm{R}=0.5^{* *}$ & $\mathrm{R}=-0.52^{* *}$ \\
\hline ROMS & $\mathrm{ns}$ & $\mathrm{R}=0.7 * * *$ & $\mathrm{R}=-0.77 * * *$
\end{tabular}

$* p<0.05 ; * * p<0.01 ; * * * p<0.0001 . \mathrm{FEV}_{1}$ : forced expiratory volume in 1 second; GDS: Geriatric Depression Scale; MMSE: Mini Mental State Examination; NO: exhaled nitric oxide; ROMS: reactive oxygen metabolites. lated this damage to a progressive increase of the systemic oxidative stress [34, 35]. The EVA study showed that subjects with the highest levels of TBARS (thiobarbituric acid reactant substances, an indicator of lipoperoxidation) presented the increased risk of cognitive decline, measured using the Mini Mental Status Examination (MMSE) [36]. Negative correlation between cognitive degree and anti-oxidant status was identified in this study [36]. It is probable that the increased levels of oxidative stress and/or antioxidant deficiencies may represent risk factors for cognitive decline, that is a major component of age-related dementing diseases and that can share the same pathological pathways with neurodegenerative processes and cerebrovascular lesions [37].

These studies can be limited by the population sample: in fact the enrolled patients were often in the age-range between 60 and 80 years and the follow up of three or four years was done. To our knowledge, no sufficient data is available on the progressive cognitive impairment during aging from younger to older subjects. In contrast with previous studies, analysing the cognitive impairment degree with MMSE, we found no differences in MMSE score between three groups, although the progressive increase of systemic and airways oxidative stress was observed. We have tested cognitive impairment in healthy elderly subjects also using GDS; elevated GDS scores were observed in many studies evaluating depressive moods in patients affected by several diseases such as COPD, which is known to be related to oxidative stress. In these studies often worse respiratory function was related to higher GDS scores. We have observed in healthy subjects progressive increase of GDS values during aging and a correlation between GDS scores and systemic and local oxidative stress; however most of the subjects were in the mild stage of depression (GDS score: 10-19) and none of the studied subjects were included into the "severe depression" group (GDS score $\geq 20$ ). We could suggest that this result is due to the early onset during life of local and systemic oxidative stress, that could be able to influence the cognitive functions in the younger subjects jet, also having a less strong effect than COPD. However a limitation of this hypothesis is the small number of analysed subjects in our study; moreover an other confounding factor could be that in the available studies the short form (15 items) of GDS is frequently used both on ill and healthy subjects; this questionnaire is based on a different score system (a score $>5$ points is suggestive of depression and a score $>10$ is almost always depression) and it is therefore difficult to compare the results.

The progressive score increase of GDS, and the significant correlation between oxidative stress and depression degree during aging are demonstrated by our study.

Major depressive disorder (MDD) and clinical depression are known to be related to oxidative stress and inflammation. It was suggested that stressors and cytokines share a common ability to impair neuronal plasticity and at the same time al- 


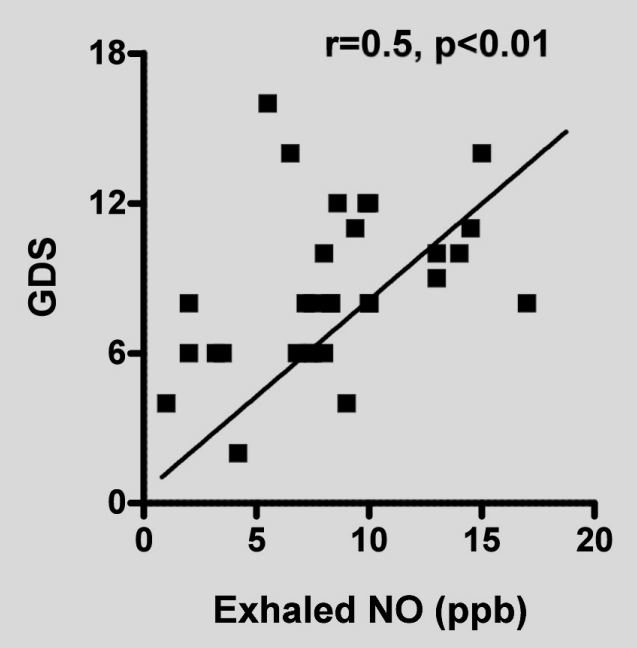

Fig. 5. - Significant positive correlation between exhaled NO and GDS score.

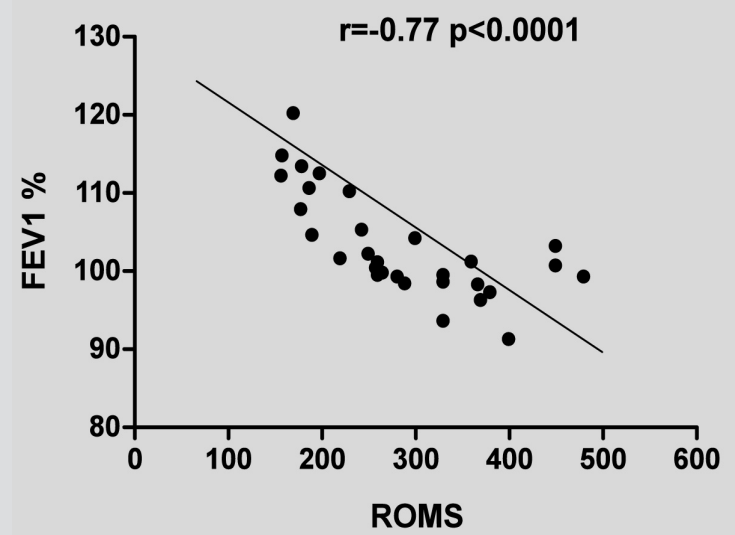

Fig. 6. - Significant negative correlation between plasmatic ROMS and $\mathrm{FEV}_{1}$.

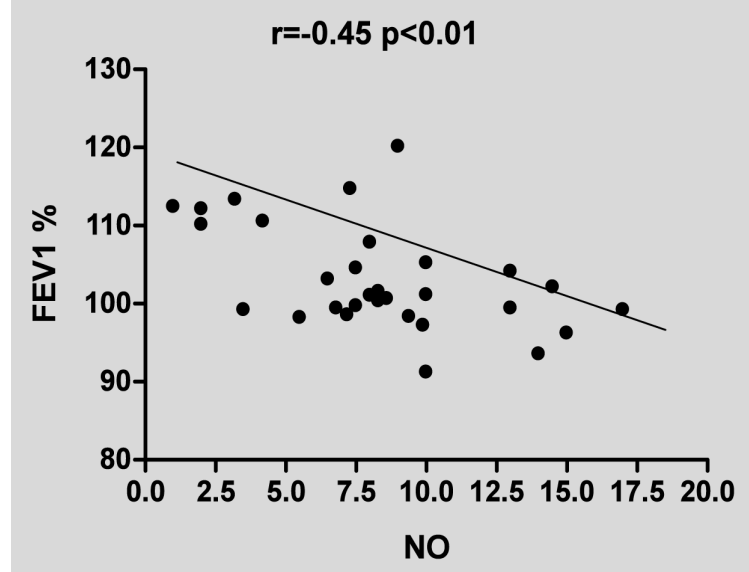

Fig. 7. - Significant negative correlation between exhaled NO and $\mathrm{FEV}_{1}$. tering neurotransmission, ultimately contributing to depression $[38,39]$. On this basis, it is possible to suggest that oxidants level and oxidants-anti-oxidants balance alterations are, at least in part, responsible also for the depression increase observed in healthy subjects during aging [40]. In accordance with this data, our results not only show a correlation between oxidative stress and airway inflammation in healthy subjects during aging, but they also could suggest a role of oxidative stress in progressive cognitive impairment. Our data, which is not conclusive due to limitations of the study, such as the small number of enrolled patients, is nevertheless suggestive of the importance of oxidative stress in cognitive functions and new studies are necessary in order to clarify the mechanisms underlying these correlations in healthy aging individuals.

\section{References}

1. Flora SJ. Role of free radicals and antioxidants in health and disease. Cell Mol Biol 2007; 53: 1-2.

2. Valko M, Leibfritz D, Moncol J, Cronin MT, Mazur M, Telser J. Free radicals and antioxidants in normal physiological functions and human disease. Int J Biochem Cell Biol 2007; 39: 44-84.

3. Droge W. Oxidative stress and aging. Adv Exp Med Biol 2003; 543: 191-200.

4. Maugeri D, Santangelo A, Bonanno MR, et al. Oxidative stress and aging: studies on an East-Sicilian, ultraoctagenarian population living in institutes or at home. Arch Gerontol Geriatr Suppl 2004; 9: 271-7.

5. Kelly FJ, Dunster C, Mudway I. Air pollution and the elderly: oxidant/antioxidant issues worth consideration. Eur Resp J Suppl 2003; 40: 70s-75s.

6. Schunemann HJ, Muti P, Freudenheim JL, et al. Oxidative stress and lung function. Am J Epidemiol 1997; 146: 939-48.

7. Donohue JF. Ageing, smoking and oxidative stress. Thorax 2006; 61: 461-62.

8. Sahl B, Webb K, Guyan PM, et al. Aberrant free radical activity in cystic fibrosis. Clin Chim Acta 1989; 181 : 65-74.

9. Gulumian M. The role of oxidative stress in diseases caused by mineral dusts and fibres: current status and future of prophylaxis and treatment. Mol Cell Biochem 1999; 196: 69-77.

10. Cantin AM, North SL, Fells GA, Hubbard RC, Crystal RG. Oxidant-mediated epithelial cell injury in idiopathic pulmonary fibrosis. J Clin Invest 1987; 79: 1665-73.

11. Malerba M, Balbi B, Spanevello A. Aging and inducedsputum cells. Chest 2005, 128: 4049-50.

12. Rahman I, MacNee W. Role of oxidants/antioxidants in smoking induced airways diseases. Free Radic Biol Med 1996; 21: 669-81.

13. Brigham KL. Oxidant stress and adult respiratory distress syndrome. Eur Respir J 1990; 11: 482s-4s.

14. Cantin AM, North SL, Hubbard RC, Crystal RG. Normal alveolar epithelial lining fluid contains high levels of glutathione. Am J Physiol 1987; 63: 152-7.

15. Morrison D, Rahman I, Lannan S, MacNee W. Epithelial permeability, inflammation and oxidant status in the airspaces of chronic smokers. Am J Respir Crit Care Med 1999; 159: 1-8.

16. Carpagnano GE, Kharitonov SA, Foschino-Barbaro MP, Resta O, Gramiccioni E, Barnes PJ. Increased inflammatory markers in the exhaled breath condensate of cigarette smokers. Eur Respir J 2003; 21: 589-93. 
17. Hazucha MJ, Bates DV, Bromberg PA. Mechanisms of action of ozone on the human lung. J Appl Physiol 1989; 67: 1534-41.

18. Gallagher M, Landfield PW, McEwen B, et al. Hippocampal neurodegeneration in aging. Science 1996; 274: 484-5.

19. Toescu EC. Normal brain ageing: models and mechanisms. Philos Trans R Soc Lond B Biol Sci 2005; 360: 2347-54.

20. Serrano F, Klann E. Reactive oxygen species and synaptic plasticity in the aging hippocampus. Ageing Res Rev 2004; 3: 431-43.

21. Droge W, Schipper HM. Oxidative stress and aberrant signalling in aging and cognitive decline. Aging Cell 2007; 6: 361-70.

22. Martinez M, Hernandez AI, Martinez N. N-Acetylcysteine delays age-associated memory impairment in mice: role in synaptic mitochondria. Brain Res 2000; 855: 100-6.

23. Banaclocha MM, Hernandez AI, Martinez N, Ferrandiz ML. N-acetylcysteine protects against age-related increase in oxidized proteins in mouse synaptic mitochondria. Brain Res 1997; 762: 256-8.

24. Ferraro FR, Chelminski I. Preliminary normative data on the Geriatric Depression Scale-Short Form (GDSSF) in a young adult sample. J Clin Psychol 1996; 52: 443-7.

25. Rahman I, MacNee W. Oxidative stress and regulation of glutathione in lung inflammation. Eur Respir J 2000; 16: 534-554.

26. Rahman I, Morrison D, Donaldson K, MacNee W. Systemic oxidative stress in asthma, COPD, and smokers. Am J Respir Crit Care Med 1996; 154: 1055-60.

27. Brennan FM, Maini RN, Feldmann M. Cytokine expression in chronic inflammatory disease. $\mathrm{Br}$ Med Bull 1995; 51: 368-84.

28. Rahman I, MacNee W. Role of transcription factors in inflammatory lung diseases. Thorax 1998; 53: 601-12.

29. Lamb NJ, Gutteridge JM, Baker C, Evans TW, Quinlan GJ. Oxidative damage to proteins of bronchoalveolar lavage fluid in patients with acute respiratory distress syndrome: evidence for neutrophil-mediated hydroxy- lation, nitration, and chlorination. Crit Care Med 1999; 27: 1738-44.

30. Nightingale JA, Rogers DF, Barnes PJ. Effect of inhaled ozone on exhaled nitric oxide, pulmonary function, and induced sputum in normal and Asthmatic subjects. Thorax 1999; 54: 1061-90.

31. MacNee W, Wiggs BB, Belzberg AS, Hogg JC. The effect of cigarette smoking on neutrophils kinetics in human lungs. N Engl J Med 1989; 321: 924-8.

32. Olin AC, Rosengren A, Thelle DS, Lissner L, Bake B, Torén K. Height, age, and atopy are associated with fraction of exhaled nitric oxide in a large adult general population sample. Chest 2006; 130: 1319-25.

33. Tsang KW, Ip SK, Leung R, et al. Exhaled nitric oxide: the effects of age, gender and body size. Lung 2001; 179: 83-91.

34. Mecocci P. Oxidative stress in mild cognitive impairment and Alzheimer disease: a continuum. J Alzheimers Dis 2004; 6: 159-63.

35. Launer LJ, Kalmijn S. Anti-oxidants and cognitive function: a review of clinical and epidemiologic studies. J Neural Transm Suppl 1998; 53: 1-8.

36. Berr C, Balansard B, Arnaud J, Roussel AM, Alperovitch A. Cognitive decline is associated with systemic oxidative stress: the EVA study. Etude du Vieillissement Artériel. J Am Geriatr Soc 2000; 48: 1285-91.

37. Berr C. Cognitive impairment and oxidative stress in the elderly: results of epidemiological studies. Biofactors 2000; 13: 205-9.

38. Sarandol A, Sarandol E, Eker SS, Erdinc S, Vatansever E, Kirli S. Major depressive disorder is accompanied with oxidative stress: short-term antidepressant treatment does not alter oxidative-antioxidative systems. Hum Psychopharmacol 2007; 22: 67-73.

39. Hayley S, Poulter MO, Merali Z, Anisman H. The pathogenesis of clinical depression: stressor- and cytokine-induced alterations of neuroplasticity. Neuroscience 2005; 135: 659-78.

40. Norris CM, Korol DL, Foster TC. Increased susceptibility to induction of long-term depression and longterm potentiation reversal during aging. $J$ Neurosci 1996; 16: 5382-92.

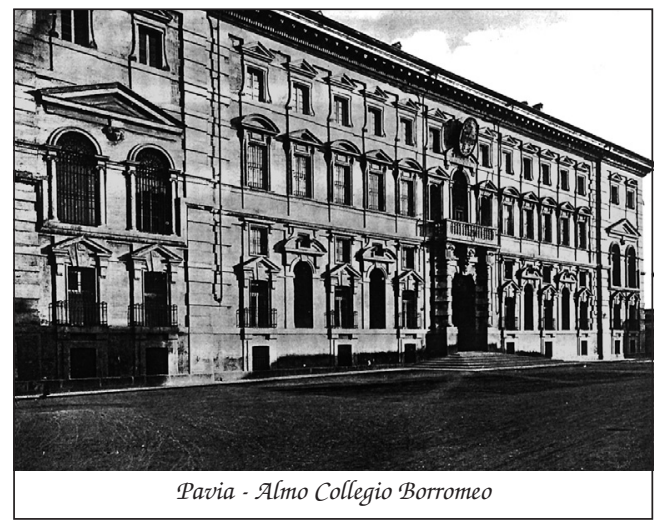

